\title{
PROCESSOS QUE LEVAM À COMPREENSÃO DE TEXTOS
}

\author{
Maria Waleska Camboim Lopes de Andrade* \\ Maria da Graça Bompastor Borges Dias"
}

\begin{abstract}
RESUMO. "Todas as crianças aprendem a falar. Essa tendência natural para adquirir a linguagem é um presente que está inscrito na herança genética que é nossa em virtude de sermos humanos." (Boysson-Bardies -1999). Como os seres humanos lidam com a linguagem? O que se sabe sobre os processos cognitivos e sociais que estão envolvidos nesta relação? O que é a compreensão e como se compreende? O objetivo deste trabalho é observar a linguagem pela perspectiva da cognição, seguindo uma linha de abordagem elaborada por Kintsch e van Dijk durante os anos de 1978 a 1983. Trata-se de uma concepção de importância por se constituir de uma natureza teórica e de um modelo empírico sobre a compreensão de textos. Especificamente, investigam-se as idéias de Perfetti, Marron e Foltz (1996) e de Weaver III, Bryant e Burns (1995), autores cujas pesquisas e idéias se afiliam a esta concepção.
\end{abstract}

Palavras-chave: linguagem, cognição, compreensão.

\section{PROCESSES THAT LEAD TO TEXT COMPREHENSION}

\begin{abstract}
All children learn to talk. This natural tendency to acquire language is a gift inscribed in the genetic inheritance that is ours by virtue of being human" - Boysson-Bardies (1999). How do people deal with language? What one knows about both cognitive and social processes that are involved on this relation? What is a comprehension and how one comprehends? This work has as aim to describe succinctly some perspectives through which different authors explain theirs ideas and research results. Particularly it was observed how to look the reading, writing and comprehension phenomena as a specific human capacity; the idea that an individual and an acquired ability is needed in order to control volunteer or unconsciously its own comprehension process. One basic aspect is presented as background: the relation between language and human cognition. It was concluded that further studies are needed for researchers to get a thorough understanding of the consequences of learning spoken and written language.
\end{abstract}

Key words: Language, cognition, comprehension.

Apresenta-se aqui um conjunto de idéias sobre como diferentes autores tratam os processos cognitivos envolvidos na linguagem e na compreensão de texto. Considera-se que estas idéias assim reunidas, de uma forma particularmente estruturada, permitem uma noção diferenciada, um distinto ângulo de visão para o campo de conhecimento que envolve o estudo de processos que levam à compreensão de textos. A base teórica destes estudos é a relação entre linguagem e cognição humana, entretida como a procura que as pessoas costumam empreender para conhecer o mundo. Trata-se de uma incursão sobre o que alguns autores como: Graesser e Zwaan (1995); Kintsch (1998); Oakhill e Yuill (1996); Perfetti, Marron e Foltz (1996); Weaver III, Bryant e Burns (1995) - vêm estudando e definindo sobre a forma como se dá a compreensão de textos, vista como um processo cognitivo, emocional e de certa forma universal. Considera-se que muito se tem ainda que melhorar para alcançar uma compreensão duradoura sobre as implicações da linguagem quanto aos processos cognitivos, e esta incursão sobre o campo lingüístico e cognitivo retratando a perspectiva de Kintsch em variadas feições é mais uma contribuição neste sentido.

\section{A COMPREENSÃO DE TEXTOS}

Procurar-se-á no presente contexto observar os processos mentais ou a forma cognitiva típica do ser humano - entender, julgar, dar sentido - como básicos para a compreensão de textos. Para representar e explicar o processo de compreensão de textos, Kintsch

* Doutora em Psicologia Cognitiva da Universidade Federal de Pernambuco-UFPE.

\# Professora Doutora do Programa de Pós-Graduação em Psicologia Cognitiva da Universidade Federal de Pernambuco-UFPE. 
e van Dijk elaboraram, entre 1978 e 1983, uma concepção teórica e um modelo empírico de compreensão. Estes vêm sendo desde então desenvolvidos por Kintsch e têm sido tomados como base para pesquisas empreendidas por outros autores, como, por exemplo, Graesser e Zwaan (1995), Oakhill e Yuill (1996); Perfetti, Marron e Foltz (1996) e de Weaver III, Bryant e Burns (1995), cujas pesquisas serão citadas no presente trabalho.

Tal formulação tem permitido delinear algumas variáveis que estão envolvidas nos processos mentais e se referem à compreensão. Aqui, acredita-se que o conhecimento a respeito deste sistema de variáveis interrelacionadas permite tornar mais clara a problemática relativa ao auxílio à compreensão de textos. Tentar-se-á a seguir expor algumas de suas características mais importantes.

\section{O MODELO DE CONSTRUÇÃO - INTEGRAÇÃO}

Segundo Kintsch (1998), a compreensão deve ser vista como: (1) uma estrutura frouxamente amarrada, isto é, compatível com a forma flexível e sensível ao contexto da compreensão humana; (2) um processo tipo bottom-up, ou seja, que filtra a percepção e preenche inferencialmente os vazios encontrados no materialestímulo do momento, não através de teorizações do percebedor, mas de (3) adaptações flexíveis a variações no meio ambiente.

Por esta perspectiva, compreender implica fazer conexões entre as idéias expressas em um texto e um conhecimento relevante anteriormente adquirido. No sentido de rastear, como se compreende, pressupõe-se que as pessoas formam "todos" coerentes, do tipo gestalt, com características elementares perceptuais e conceituais. Considera-se que ocorre uma espécie de seleção mental de estímulos que são externos à consciência, utilizando como critério a procura de coerência no que se observa. Além disto, admite-se que dois fatores principais são capazes de chamar a atenção do sujeito em um processo de compreensão: o que está relacionado com os seus objetivos e motivações e as características específicas da situação em que a compreensão está ocorrendo.

Para Kintsch (1998), compreender é compor um modelo mental que envolve um processo de construção e integração. As coisas se passariam da seguinte forma: primeiro, as representações mentais são formadas por regras de produção fracas que, inicialmente, levam a um resultado redundante e às vezes até contraditório; em seguida, sofrem um processo de integração que resulta numa bem-estruturada representação mental.
Por serem fracas, as regras de controle instanciam tanto o sentido certo como o errado das palavras, ou formam, ao mesmo tempo, tanto as inferências relevantes como as irrelevantes. A construção do sentido "correto" ou contextualmente apropriado resulta do processo de integração que, rapidamente, desativa as construções contextualmente não apropriadas.

Kintsch (1998) distingue três níveis de representação cognitiva que adviriam da compreensão de textos escritos: (1) o código de superfície, o qual preserva o palavreado exato e a sintaxe das orações; (2) o texto base, que contém as proposições do texto explícito numa forma que preserva o significado, mas não o palavreado ou a forma exata do texto (inclui algumas poucas inferências necessárias para estabelecer a coerência do texto) e (3) o modelo situacional, que é uma representação mental daquilo que é explicitamente mencionado ou inferencialmente sugerido no texto (a maioria das inferências geradas na compreensão do texto são partes do modelo situacional construído, segundo Graesser \& Zwaan, 1995). Contudo, explica Kintsch que a representação final resultante do processo de compreensão é unitária.

Um grande desafio para os que adotam esta perspectiva é estabelecer quais as principais regras que ativariam o modelo de construção-integração ou quais as variáveis mais relevantes no processo de compreensão e o que exatamente as torna assim.

\section{Variáveis envolvidas na compreensão}

$\mathrm{Na}$ atividade de compreensão, os autores distinguem os processos básicos, os quais poder-se-ia dizer que são mais "mecânicos", dos de alto nível, os quais exigiriam uma maior capacidade de abstração ou de elaboração mental. Algumas entidades importantes vistas como de nível básico seriam a memória de trabalho (uma melhor memória de trabalho implica em uma compreensão mais especializada) e os chamados processos léxicos (por exemplo: o conhecimento da estrutura ortográfica). As principais variáveis de alto nível seriam: o fazer inferências (sobre informações que estão apenas sugeridas no texto ou que envolvem uma gama de conhecimentos anteriores sobre o assunto tratado) e o controle ou monitoramento do que está sendo compreendido.

Os tipos de relações ou a posição hierárquica destas variáveis que atuam no processo de compreensão ainda não estão completamente claros e têm até gerado controvérsias entre os estudiosos do assunto; o que torna ainda mais complicado apresentar um apanhado coerente e objetivo do domínio de conhecimento a respeito. Contudo, tentar-se-á aqui reunir alguns resultados de pesquisas apresentados por 
diferentes autores que denotam informações relevantes sobre estas variáveis.

\section{As variáveis de níveis alto e baixo}

Com respeito à questão sobre qual a importância relativa das variáveis de níveis básico e alto, Oakhill e Yuill (1996), por exemplo, reportam-se, especialmente, ao papel dos fatores de alta ordem na compreensão. Estes são apresentados como sendo: compreender a estrutura do texto, inferir e monitorar. Essas autoras procuram definir o que distinguiria um leitor habilidoso de um não habilidoso ou de compreensão pobre. $\mathrm{O}$ primeiro deve ter um controle sobre quais as inferências que pode fazer, além de precisar entender a estrutura do texto (por exemplo, identificar o personagem principal, seus motivos, seguir o foco e extrair o tema principal). $\mathrm{O}$ segundo pode não se dar conta de que não entendeu o texto ou uma parte específica deste e pode também não saber o que fazer quanto à sua pobre compreensão quando consegue atinar com esta.

As pesquisas de Oakhill e Yuill (1996) comparam crianças que, tendo a mesma idade e possuindo igual habilidade no processamento básico, diferenciam-se quanto aos fatores de alto nível. Esta diferenciação é feita com base em alguns testes, tais como medidas de precisão na leitura (reconhecimento de palavras no contexto) e medidas de compreensão (habilidade em responder a uma série de questões no final da leitura de uma passagem). Algumas destas medidas, da forma como foram feitas por Oakhill e Yuill (1996), são criticadas por Perffetti, Marron e Foltz (1996).

Para estes últimos autores, primeiro viriam as falhas no processo léxico e na memória de trabalho. Oakhill e Yuill (1996), contudo, alegam não ter achado diferenças entre sujeitos habilidosos em compreender e os de pouca habilidade, no que diz respeito à decodificação de palavras, de maior ou menor freqüência, nem quanto à automaticidade da decodificação. Em outras palavras, suas pesquisas depararam-se com crianças pobres em compreensão, que não conseguiam responder às perguntas no final da passagem que liam, mas não tinham dificuldade no nível das palavras - liam com fluência e facilidade. Por outro lado, encontraram crianças que mostravam uma decodificação lenta e laboriosa, mas eram boas na compreensão.

Essas autoras afirmam que os pobres em compreensão não são habilidosos no nível das inferências. Para verificar a possibilidade de haver uma dificuldade na memória de longo prazo, as autoras fizeram um experimento em que ora as crianças podiam consultar o texto, ora não. Descobriram que, mesmo com o texto disponível, as pobres em compreensão foram incapazes de responder em alta proporção a questões que requeriam inferências.

Para Oakhill e Yuill (1996), a explicação pode estar na qualidade da representação da informação literal, embora tenham observado que leitores pobres em compreensão podem ser bons em lembrar informações verbais. Estabeleceram então o que supõem ser as razões para a pobreza nas inferências: (1) a falta de conhecimento geral para fazê-las; (2) os leitores poderem achar que a inferência é legitima, mas terem dificuldade em acessar o conhecimento relevante e integrá-lo ao texto por limitação de capacidade ou (3) poderem não se dar conta de que é necessário inferir ou mesmo de que é permitido fazê-lo. As autoras afirmam que existem evidências apoiando as duas últimas explicações; observa-se, entretanto, que as mesmas não apontam quais seriam estas capacidades limitadas, nem por que o seriam. Mais ainda, seria principalmente num contexto de experimentação que se justificaria o leitor achar que inferir não constituiria uma atividade permitida.

Relativamente ao monitoramento, Oakhill e Yuill (1996) relatam os seguintes experimentos: para saber se os leitores pobres no entendimento e os habilidosos na compreensão diferiam também quanto a seguir a pista de suas próprias compreensões, pediam às crianças que lessem e descrevessem aparentes inconsistências em histórias pequenas. Outros tipos de histórias (consistentes e não resolvíveis) serviam como controle. A inconsistência estava no comportamento de um adulto com relação a uma criança. O leitor só poderia responder corretamente às questões, após a leitura, se a anomalia fosse resolvida corretamente. Uma resposta errada significaria que a criança não concordava com as normas de comportamento, portanto não deveria achar a história inconsistente. Poucas crianças responderam de forma incorreta. Tentaram também testar a memória em um aspecto crucial da história. Descobriram que quando a informação que solucionava a inconsistência estava junto desta no texto, todos se saíam bem; quando estavam separadas, os leitores de compreensão pobre se saíam pior. Poderse-ia dizer que tal resultado corrobora a noção de que sem certa capacidade de memória de trabalho o leitor teria menores resultados na compreensão, mesmo dominando a técnica de inferir. Neste caso, não haveria por que tais autoras discordarem de Perfetti, Marron e Foltz (1996).

Oakhill e Yuill (1996) concluem que a integração das informações vindas de diferentes partes do texto é muito difícil para os não-habilidosos e isto deve estar 
relacionado à memória de trabalho. Após uma revisão sobre várias pesquisas no assunto, estas autoras apontam para o que chamam de uma "sugestão óbvia", que é a de que os leitores mais habilidosos são melhores em fazer inferências e em monitorar suas compreensões e também em interpretar e derivar estruturas das histórias. Contudo, como explicam Oakhill e Yuill (1996), não há dados sobre a direção desta ligação. Adotam então a sugestão de Tummer (citado por Oakhill \& Yuill, 1996) de que é a prática de leitura que aumenta de maneira crescente a capacidade da memória de trabalho, e não o inverso.

Os autores concordam quanto às interações gerais entre as variáveis, embora não quanto às particularidades. Perfetti, Marron e Foltz (1996), por exemplo, sugerem que provavelmente há quem passe a vida toda fazendo inferências e quem não as faça nunca. Relativamente às evidências que associam a habilidade em compreender a fazer inferências, estes autores perguntam: o que normalmente se toma como inferência? Para esses autores, fazer inferências depende do conhecimento e dos objetivos do leitor em conexão com as propriedades do texto. Duvidam da suposição de que se trata de uma característica estável e individual.

Para Perfetti, Marron e Foltz (1996), nem mesmo a idéia de que uma falha em inferir seja marca de uma compreensão pobre está clara. Argumentam que, se isto fosse verdade, também não se saberia ainda se trata de uma característica do indivíduo ou da representação do conhecimento. Para estes autores, um leitor que está motivado para construir uma representação coerente e tem o conhecimento necessário para representar a informação do texto fará as inferências necessárias. Os debates sobre as inferências on-line continuam fortes e as tentativas para demonstrá-las são sofisticadas, devido às dificuldades em fazê-lo.

\section{A GERAÇÃO DE INFERÊNCIAS}

Não obstante, as pesquisas de Graesser e Zwaan (1995) sobre a geração de inferências e a construção de modelos situacionais enquadram-se neste último tipo. Estes autores investigaram a representação e o processamento de modelos situacionais, querendo saber quais os processos que seriam centrais quando textos narrativos são compreendidos por leitores adultos. Neste sentido, procuraram identificar: (1) quais as classes de inferências que os leitores geram enquanto constroem o modelo situacional; (2) quais as fontes de informação e os mecanismos processuais que produzem as inferências e (3) a extensão pela qual as inferências são baseadas no processo léxico (herdadas diretamente do conhecimento sobre o mundo, dentro de itens léxicos explícitos no texto) e em situações novas (não partem de nenhum item léxico, mas algumas são produzidas pela manipulação ativa de uma espécie de "diretor mental").

Muitas das inferências que são geradas quando um modelo situacional é construído baseiam-se no conhecimento de mundo que os leitores já possuem. Como explicaram Oakhill e Yuill (1996), este conhecimento pertence à memória de longo prazo, que é ativada durante a compreensão, instanciando um conjunto de informações como inferências para o modelo situacional. Tal conhecimento pode ser genérico: estruturas - estereótipos, esquemas - ou específico, uma experiência particular ou um texto compreendido no passado. Os autores explicam que estas últimas tomam mais tempo e recursos de processamento, por não serem automatizadas. Tais inferências (do conhecimento) são distintas de inferências baseadas na lógica (exemplo: cálculo preposicional, prova de teoremas) ou das inferências quantitativas (derivadas de fórmulas).

Os autores distinguem, em textos narrativos, seis tipos de inferências baseadas no conhecimento: (1) meta superordenada (que motiva uma ação intencional no agente); (2) meta ou ação subordinada (plano ou ação que especifica como uma ação intencional do agente é alcançada); (3) antecedente causal (ponte entre a oração explícita que foi compreendida e a passagem contextual prévia); (4) conseqüência causal (é feita numa corrente causal prevista, desdobrada a partir de a oração explícita ter sido compreendida; não se baseia em emoções); (5) emoção do personagem (emoção experimentada através de um personagem em resposta à ação ou evento que foram compreendidos); (6) estado (a inferência é um estado em andamento, a partir da estrutura de tempo do enredo da história que não é ligado como causalidade aos episódios do enredo). Tais inferências são extratextuais, baseadas no conhecimento. Graesser e Zwaan (1995) explicam que esta classificação não esgota as classes de inferências que são potencialmente geradas durante a compreensão.

Uma subclassificação distingue as inferências que são geradas on-line (durante o processo de leitura) e off-line (numa recuperação posterior da tarefa). Para garantir uma verificação das inferências on-line, Graesser e Zwaan (1995) propõem uma coleta de protocolos verbais para uma amostra de leitores que se pronunciam quanto à sua compreensão do texto, 
oração por oração. Utilizam três tipos de protocolo: (1) pensando em voz alta; (2) respondendo a questões e (3) fazendo questões, e um chamado método trifásico.

Graesser e Zwaan (1995) estudam os leitores que querem compreender o enredo a uma profundidade suficiente para extrair os pontos principais da história. Segundo estes autores, o modelo de Kintsch e van Dijk (ver Kintsch, 1998) tem um mecanismo sistemático computacional para gerar as inferências necessárias ao estabelecimento de coerência local no texto. Conforme este modelo, sempre que uma oração nova não tem um argumento de frase substantiva que combine com um argumento existente na memória de trabalho, o leitor tenta construir uma inferência em ordem para estabelecer uma coerência local. Graesser e Zwaan (1995) propõem um modelo construcionista no qual o leitor tenta estabelecer coerência causal através da construção de inferências baseadas em antecedentes causais e em metas superordenadas, durante a compreensão.

O modelo construcionista faz ressurgir o princípio do esforço para significar de Bartlett (citado por Graesser \& Zwaan, 1995), o qual afirma que os leitores tentam construir um sentido fora do texto, além de interações sociais e percepção. Baseia-se ainda em três pressuposições críticas com relação ao leitor, o qual provavelmente: (1) constrói inferências que estão relacionadas com seus objetivos; (2) esforça-se para explicar por que ações, eventos e estados são mencionados no texto e (3) tenta construir uma representação que tenha sentido coerente tanto a nível local como global.

Todas as classes de inferências são geradas online, contanto que o leitor, para tanto, tenha o prérequisito necessário de conhecimento de mundo. Uma segunda preocupação de Graesser e Zwaan (1995) refere-se à origem das inferências. Por isto, distinguem dois conjuntos destas: as baseadas no léxico ou herdadas diretamente do conhecimento de mundo que está estocado em conteúdos explícitos de palavras do texto (palavras-conteúdo, substantivos, adjetivos e principais verbos) e as de situações novas, que não casam diretamente com nenhuma informação contida nos itens léxicos, mas são produto de mecanismos de processamento mais complexos.

Os principais mecanismos de processamento de situações novas seriam: (1) as "deixas compostas", nas quais dois ou mais itens léxicos juntos fornecem acesso a uma estrutura de conhecimento específica ou genérica; (2) "explicações sintetizadas", produto de vários passos do raciocínio, que reúne fragmentos de conhecimentos vindos de variadas fontes de informação; (3) "operações do diretor mental", nas quais as propriedades vêm a foco na medida em que o diretor mental focaliza entidades particulares; são limitadas pelo contexto situacional único da narrativa.

Depois de um procedimento de investigação bastante sofisticado, Graesser e Zwaan (1995) apresentam duas possíveis explicações extremas sobre como o conhecimento está estocado nos itens léxicos: ou o léxico é limitado ao código fonológico e sintático e às características semânticas necessárias para fazer as computações sintáticas, ou adiciona características semânticas que seriam parte de teorias semânticas não linguiísticas, incluindo assim o conhecimento de mundo.

Os resultados das comparações entre as inferências baseadas no léxico e as de situações novas surpreenderam esses autores: os pontos da codificação de inferências foram significativamente mais baixos para inferências baseadas no léxico do que para as inferências de situações novas. Graesser e Zwaan (1995) explicam que a maioria dos pesquisadores esperaria que inferências baseadas no léxico fossem mais rápidas, por serem diretamente herdadas de itens lexicais aprendidos e acionados por palavras-conteúdo na oração explícita; ao contrário das inferências situacionais novas, que, presumivelmente, são produto de processos construtivos consumidores de tempo e operam contextualmente no modelo situacional específico.

Esses autores apresentam algumas explicações para este resultado contra-intuitivo. A primeira referese à composição de itens léxicos em relação a itens singulares, tal como foi estudada por eles. Conforme a teoria, a construção de inferências é mais rápida quando é produto de uma composição. Para isto, as inferências novas deveriam ser produto de estruturas de conhecimento genérico e específico disponibilizadas pela composição de palavras. O que ocorreu então pode ter sido que as inferências de fato eram produto de explicações sintéticas ou de operações do diretor mental, mas não de composições acessando estruturas de conhecimento.

Uma segunda explicação refere-se à idéia de que a novidade de inferências em situações novas atrai a atenção focal dos leitores e aumenta a força da codificação. A informação nova é o que diferencia a situação única de conhecimento genérico de outras situações armazenadas na memória, fornecendo índices distintos para sua organização e recuperação. Sendo mais relevante e distinta para o modelo situacional, a informação nova pode desempenhar um papel central na geração de inferências. Graesser e Zwaan (1995) reforçam esta explicação citando 
evidências estabelecidas por outros autores de que a informação nova é detectada muito rapidamente durante a percepção e a compreensão. Também citam a importância da novidade e da incerteza durante a construção de sentido proposta por Berlyne (citado por Graesser \& Zwaan, 1995).

Observou-se, assim, a partir destes estudos e explicações descritos, que não é apenas a dificuldade em medir que torna difícil o entendimento sobre o processo de compreensão, mas a própria natureza complexa do fenômeno. Poder-se-ia assim talvez dizer que existem aspectos compreensivos doadores de sentido que ultrapassam os mecanismos cerebrais/mentais usados na compreensão. Mais ainda, conseguir ou não entender um texto é também um processo problemático, no sentido de que nem sempre o leitor sabe que não está entendendo, nem sabe lidar com o fato de saber ou não saber.

\section{SEGUIR A PISTA DA PRÓPRIA COMPREENSÃO}

Weaver, Bryant e Burns (1995) compõem um histórico a respeito do que vem se estudando a respeito do processo de monitoramento que pode também ser chamado de "calibragem da compreensão" ou de "metamemória para textos". Segundo estes autores, podem-se considerar três fases principais em que se verificaram compreensões distintas sobre este processo.

$\mathrm{Na}$ primeira fase encontram-se os estudos de Glenberg, Wilkinson e Epstein (citados por Weaver, Bryant, \& Burns, 1995) do início dos anos 1980, os quais concluíram que os leitores são capazes de monitorar suas compreensões, mas apenas sob circunstâncias altamente condicionadas ou não naturais, e, mesmo assim, de forma marginal (correlações abaixo de 0,20 entre suas previsões quanto à própria compreensão e seus acertos). Weaver, Bryant e Burns (1995) classificam esta fase como o estágio no qual se acredita que os leitores não são capazes de monitorar suas compreensões.

Numa segunda fase, Weaver, Bryant e Burns (1995) citam as pesquisas de Weaver (1990) e de Maki, Foley, Kajer, Thompson e Willert (1990; 1992), as quais concluem sobre a raridade da ocorrência de uma compreensão que seja do tipo "ou se entende tudo ou não se entende nada". Argumentam que se deve dar mais de uma chance para os leitores demonstrarem suas habilidades. Weaver, Bryant e Burns (1995) chamam esta fase de estágio em que se admite que os leitores são capazes de calibrar o entendimento, embora não muito bem.
Esses autores apontam algumas causas para este fato de o monitoramento não ser muito bom: (1) este dependeria da intuição do leitor, a qual pode estar errada e (2) os pesquisadores não sabem a técnica adequada para medir o monitoramento da compreensão (por exemplo: há uma diferença nas correlações entre as previsões e acertos dos sujeitos, quanto a sua compreensão, quando os pesquisadores variam a questão de: "quão bem você acha que vai compreender?" para "quão pouco acha que compreenderá?").

$\mathrm{Na}$ terceira e última fase, foram feitas revisões de literatura a respeito do que se conhece sobre monitoramento (Britton \& Gulgoz, 1991, citados por Weaver, Bryant, \& Burns, 1995) e pesquisas como as de McDaniel e Einstein (1986, 1988, citados por Weaver, Bryant, \& Burns) sobre as variações de resultados quanto à memória para textos com relação a diferentes tipos de aumento no esforço cognitivo durante a tarefa, as quais demonstraram a noção de material de processamento apropriado (MAP). Esta afirma que manipulações no processamento levam a um aumento da memória para textos, mas apenas na medida em que tal processamento é adicional para um processamento antes já induzido pelo próprio texto.

Por exemplo: para esses autores, os textos narrativos induzem, naturalmente, um processamento relacional. Os leitores desta modalidade processam as partes temáticas globais do texto, mas não vão necessariamente prestar atenção aos detalhes. Dessa forma, os processos que realçam o processamento de informações temáticas não produzirão efeitos na memória, enquanto os processos que encorajam a atenção para os detalhes vão somar na memorização do texto. Por outro lado, têm-se os textos expositores que induzem um processamento orientado para os detalhes. Um aumento na memorização deste tipo de textos deve ser provocado por processos que induzem um processamento temático. Weaver, Bryant e Burns (1995, p.179) classificam estas novas informações, as quais associam ao modelo de Kintsch, citado, como a terceira fase na compreensão sobre o monitoramento, a qual chamam de "Ah! Então estas são as variáveis importantes!".

Weaver, Bryant e Burns (1995) descrevem quais as variáveis que consideram importantes e os experimentos que fizeram para comprová-las. Estas incluiriam: (a) as variáveis "relativas aos sujeitos" (que pretendem explicar como as características individuais podem afetar o monitoramento da compreensão de uma certa forma); (b) as "associadas ao processamento" (que verificam a calibragem em diferentes tipos de tarefas de compreensão - lembrar, 
reconhecer, inferir e resumir - induzidas tanto pelo próprio material como por instruções explícitas) e (c) as variáveis "associadas aos estímulos" (para explorar as diferenças na habilidade dos leitores em monitorar tipos de textos distintos, tais como os que foram melhorados por análises de legibilidade dos textos ou por revisões destes). Os autores esclarecem que este último conjunto de variáveis é o único que está sob controle direto do autor.

Dentre os aspectos que descrevem destaca-se a informação de que diferentes níveis de monitoramento podem ser alcançados para textos conjugados em distintos graus de dificuldade. Segundo esses autores, ao comparar crianças com a mesma idade cronológica, deve-se esperar que os leitores mais avançados apresentem um pico (maior nível de monitoramento) diferente do dos leitores menos habilidosos.

Weaver, Bryant e Burns (1995) explicam que, provavelmente, a habilidade em monitorar os textos em um certo nível indica que os leitores passaram a "controlar" este nível de textos e estão prontos para textos mais difíceis. Especulam sobre a origem desta habilidade metacognitiva, a qual deve ser mediada pelos recursos disponíveis na memória de trabalho. Explicam que à medida que os processos básicos de leitura se tornam mais eficientes, consumindo assim menos espaço na memória de trabalho, estes espaços provavelmente tornam-se livres para atividades como o monitoramento da compreensão.

Mais uma vez, observa-se a alusão à necessidade de um certo grau de capacidade de memória de trabalho para conseguir executar tarefas envolvendo variáveis de alto nível. É possível associar-se tal idéia àquela que fala da habilidade em lidar com a estrutura dos textos (se uma informação-chave está perto ou não, no texto, da passagem que necessita dela para ser compreendida). Mais ainda, pode-se associar também esta referência à capacidade da memória de trabalho de aceitação ou confirmação do sentido, da norma ou do que seja que se tenha interiorizado como conhecimento de mundo. Além disto, é preciso ter em mente ainda os resultados de Graesser e Zwaan (1995), que apontam para a geração de inferências mais rápida quando tratam de situações novas em leitores que procuram compreender e em textos narrativos.

Tais noções corroboram também as idéias de Perfetti, Marron e Foltz (1996), segundo as quais a habilidade em monitorar a própria compreensão varia com o treinamento em compreender e as pessoas que são menos treinadas demonstram fazer inferências mais pobres do aquelas que são mais treinadas. Por exemplo, esses autores observaram se os leitores podiam detectar (lembrar ou comentar) inconsistências (palavras misturadas ou afirmações contraditórias, em diferentes parágrafos) num texto curto. Encontraram um padrão típico de resultados que pode assim ser resumido: alguns leitores (tanto crianças como adultos) podiam detectar as inconsistências e outros não; os leitores menos habilidosos ou mais jovens, embora tidos como não detectores de inconsistências, em geral, detectavam inconsistências locais (as quais podem interferir na formação de uma representação baseada no texto), notavam palavras misturadas e comentavam sobre o pouco sentido semântico de frases; os leitores de habilidade alta detectavam inconsistências globais, as quais interferem na formação de um modelo situacional, por exemplo, se os parágrafos apresentavam tópicos não relacionados.

Perfetti, Marron e Foltz (1996) não concordam com a idéia de que as falhas no monitoramento e em fazer inferências sejam possíveis problemas gerais na compreensão. Para estes autores, tais fatores de alto nível dependem do conhecimento. Seus argumentos são os seguintes: uma pessoa pode saber que não está entendendo, portanto não está encontrando problemas em monitorar sua compreensão, mas em entender; mais ainda, se se considera que monitorar a compreensão refere-se à habilidade em detectar inconsistências, neste caso, são os próprios sujeitos que parecem criálas em seus modelos mentais.

Como são formadas tais inconsistências? Os autores apresentam duas hipóteses: (1) seriam uma característica geral e estável de falhas em monitorar a compreensão ou (2) é possível que os sujeitos as tolerem, e mesmo que as criem por causa de um conhecimento insuficiente. Sem o conhecimento adequado constroem elementos incompatíveis em seu modelo mental. Assim, as inconsistências e imprecisões no modelo mental seriam fruto não de uma falha no monitoramento, mas de uma falta de conhecimento. Este seria a causa do tipo de atividade de compreender que normalmente se atribui ao processo de monitoramento.

Ainda segundo Perfetti, Marron e Foltz (1996), a compreensão exige uma espécie de auto-reflexão sobre a própria atividade de leitura e entendimento, ou seja, exige um controle ou monitoramento. Assim, um leitor utiliza, para saber se compreende um texto, um conjunto de processos metacognitivos, sendo que a estratégia mais geral usada para monitorar $o$ entendimento seria o próprio objetivo que todo leitor adota: o de obter significado ou o de realizar um esforço para conseguir uma representação coerente. Um monitoramento efetivo deve assim levar à 
reparação da falta de compreensão. Mas o que seria uma falta de compreensão?

Perfetti, Marron e Foltz (1996) afirmam que existem muitas coisas que caracterizam uma compreensão pobre e que é difícil descobrir como todas estas se interconectam em torno de alguns problemas fundamentais de processamento causal, pois isso requer uma atenção cuidadosa aos componentes cuja contribuição fundamental foi estabelecida teórica e empiricamente. Consideram que para um leitor formar uma representação interpretada e integrada é preciso ele possuir um conhecimento relevante do texto e uma habilidade em leitura.

Segundo Perfetti, Marron e Foltz (1996), tem sido demonstrado que o conhecimento num domínio está associado à compreensão de textos neste domínio. Eles criticam outras abordagens que vêm considerando o conhecimento como um componente extra, como não sendo parte intrínseca da compreensão, um fator de ruído. Outra linha entende o papel do conhecimento como associado a hábitos intelectuais surgindo do aprendizado e da educação.

Para esses autores, o conhecimento é a base para a o monitoramento e para as inferências. Quando não se conhece um conceito não se consegue entender nada do que se fala a respeito, e isso implica também dificuldades com o processamento léxico e com a memória de trabalho. O conhecimento anterior seria, portanto, a principal categoria dentro do processo de compreensão.

\section{CONCLUSÃO}

O presente estudo tratou de variáveis essenciais para a compreensão de textos sob a ótica dos processos cognitivos inerentes à mente humana quando em seu funcionamento lingüístico. Trata-se de uma relação de estudos que tomam principalmente o aspecto individual. Entretanto, não se pode perder de vista o caráter cultural característico da linguagem, de que é um indicador a necessidade prévia de interação social e de experiências dentro de um meio social, levando a uma forma especificamente humana de comunicação e interpretação do mundo ou da realidade existente. Os processos de compreensão de textos dizem respeito não apenas a uma questão individual de monitoramento da compreensão e de produção de inferências relativamente à informação apreendida, mas também à leitura mais geral que o indivíduo possa incorporar ao que está tentando compreender, a qual advém de sua vivência e aquisições anteriores. Necessário dessa forma é que se conheçam e se coloquem em uníssono os dois aspectos da compreensão de textos.

\section{REFERÊNCIAS}

Boysson-Bardies, B. (1999). How language comes to children: From birth to two years. Cambridge: The MIT Press.

Graesser, A. C. \& Zwaan, R. A. (1995). Inference generation and the construction of situation models. In C. A. Weaver III, S. Mannes \& C. R. Fletcher (Eds.), Discourse comprehension: Essays in honor of Walter Kintsch (pp.117-127). Hillsdale: Lawrence Erlbaum.

Kintsch, W. (1998). Comprehension: Paradigm for cognition. Cambridge: Cambridge University Press.

Oakhill, J. R. \& Yuill, N. (1996). Higher order factors in comprehension disability: Processes and remediation. In C. Cornoldi \& J. Oakhill (Eds.), Reading difficulties: Processes and intervention (pp. 69-92). Mahwah: Lawrence Erlbaum.

Perfetti, C. A.; Marron, M. A. \& Foltz, P. W. (1996). Sources of comprehension failure: Theoretical perspective and case studies. In C. Cornoldi, \& J. Oakhill (Eds.), Reading difficulties: Processes and intervention (pp. 137-165). Mahwah: Lawrence Erlbaum.

Weaver, C. A.; Bryant, D. S. \& Burns, K. D. (1995). Comprehension monitoring: Extension of Kintsch and Van Dijk model. In C. A. Weaver. III, S. Mannes, C. R. Fletcher (Eds.), Discourse comprehension: Essays in honor of Walter Kintsch (pp.177-193). Hillsdale: Lawrence Erlbaum.

Recebido em 05/09/2003 Aceito em 05/04/2004

Endereço para correspondência: Maria Waleska Camboim Lopes de Andrade. Cond. Village Atlântico Sul, casa D6, Seixas, CEP 58035-550, João Pessoa-PB. E-mail: wcamboim@uol.com.br 